\title{
Evolución microestructural durante la transformación de la estructura pirocloro en perovskita en láminas de $(\mathrm{Pb}, \mathrm{La}) \mathrm{TiO}_{3}$
}

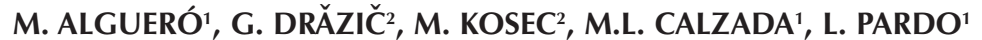 \\ ${ }^{1}$ Instituto de Ciencia de Materiales de Madrid, CSIC. Cantoblanco 28049, Madrid. Spain. \\ ${ }^{2}$ Jožef Stefan Institute. 61000 Lubljana. Slovenia.
}

\begin{abstract}
Es conocido que se produce una transformación de estructura pirocloro a perovskita durante el calentamiento rápido de láminas delgadas ferroeléctricas de titanato de plomo modificadas con $\mathrm{La}$, preparadas por sol-gel. La deficiencia de $\mathrm{Pb}$ causada por la volatilización de $\mathrm{PbO}$ en los primeros momentos del tratamiento térmico no inhibe la transformación. Se ha estudiado, por microscopía electrónica de transmisión, la evolución microestructural asociada a esta transformación, que ocurre en un medio que en promedio es deficiente en $\mathrm{Pb}$. Con este fin, se prepararon muestras para microscopía, tanto del plano de la lámina como secciones transversales, a partir de dos láminas en las que la transformación se encontraba en estadios diferentes. Los experimentos pusieron de manifiesto que la fase con estructura pirocloro se encontraba homogéneamente distribuida a lo largo del espesor de la lámina, y que su morfología era muy similar a la de la fase ferroeléctrica. La combinación de las técnicas de microdifracción y microanálisis permitió identificar granos individuales que no tenían la estructura perovskita, y establecer que presentaban una deficiencia de $\mathrm{Pb}$ mayor que el promedio de la lámina. La microscopía electrónica de transmisión también puso de manifiesto fenómenos de crecimiento de poro, de grano, y del grado de texturación local durante la transformación.
\end{abstract}

Palabras claves: Ferroeléctricos, laminas delgadas, mecanismos de cristalización, microscopía electrónica de transmisión.

Microestructural evolution during the pyrochlore to perovskite transformation in $(\mathrm{Pb}, \mathrm{La}) \mathrm{TiO}_{3}$ thin films

A pyrochlore to perovskite transformation is known to occur during the rapid heating of sol-gel prepared La modified lead titanate ferroelectric thin films. This transformation is not inhibited by the Pb deficiency caused by $\mathrm{PbO}$ volatilisation at the initial stages of the thermal treatment. The microstructural evolution associated with this transformation occurring in the $\mathrm{Pb}$ deficient film has been studied by transmission electron microscopy. Plan view and cross section specimens were prepared from two films at different stages of the transformation. Experiments showed that the pyrochlore phase was homogenously distributed across the film thickness, with a very similar morphology to that of the ferroelectric phase. The combination of microdiffraction and microanalysis allowed identifying single grains that had not the perovskite structure, and were more $\mathrm{Pb}$ deficient than the film. Pore growth, grain growth, and growth of local texturing were observed along with the transformation.

Keywords: Ferroelectrics, thin films, crystallisation mechanism, Transmission electron microscopy.

\section{INTRODUCTION}

The mechanism of the perovskite structure formation during the thermal annealing of sol-gel amorphous layers is known to comprise the formation of an intermediate phase (13). This phase has been identified either as a pyrochlore type structure or as a fluorite structure. The use of rapid thermal annealing with heating rates of several tens of ${ }^{\circ} \mathrm{C} \mathrm{s}^{-1}$ does not modify the mechanism, though it accelerates the transformation $(4,5)$. For lead zirconate titanate (PZT) films, a Pb deficiency, defined as a $\mathrm{Pb} /(\mathrm{Ti}+\mathrm{Zr})$ atomic ratio smaller than the nominal one of the perovskite, as that caused by $\mathrm{PbO}$ volatilisation has been shown to inhibit the transformation, appearing then the intermediate phase as a second phase in coexistence with the perovskite. This causes the ferroelectric properties of the film to degrade as the second phase is not polar (6).

This does not seem to be the case for lanthanum modified lead titanate (PTL) thin films. We showed in a previous investigation that the intermediate phase (a pyrochlore type structure) to perovskite transformation was able to continue after significant $\mathrm{PbO}$ volatilisation in $\mathrm{Pb}$ deficient, defined in this case just as the $\mathrm{Pb} / \mathrm{Ti}$ ratio, films (7). Phases were studied by $\mathrm{X}$-ray diffraction (XRD) and the $\mathrm{Pb} /$ Ti ratio was monitored by energy dispersive $\mathrm{X}$-ray analysis (EDS) in a scanning electron microscope. Although the occurrence of the transformation and some of its features were well established, others could not be investigated with the techniques used. An important question that could not be answered was whether the perovskite formed was also $\mathrm{Pb}$ deficient or had the nominal composition. In the latter case, a highly $\mathrm{Pb}$ deficient third phase had to remain after the transformation. Neither could be investigated whether the perovskite nucleation process was heterogeneous, i.e. it started at the substrate/layer interface, or it was a homogenous nucleation process. We present here a transmission electron microscopy (TEM) study on two PTL films at different stages of the phase transformation. The microstructural evolution associated with the transformation is described, and the implications for the questions just raised are discussed. 


\section{EXPERIMENTAL PROCEDURES}

A precursor solution with a $\mathrm{Pb}_{088} \mathrm{La}_{008} \mathrm{TiO}_{3}$ nominal composition was synthesised by a diol based sol-gel method described elsewhere (8). The solution was deposited onto $\mathrm{Pt} / \mathrm{TiO}_{2} / \mathrm{Si}(100)$ substrates by spin coating, and the resulting layers were dried on a hot plate at $350^{\circ} \mathrm{C}$ in air. Deposition and drying were repeated three times in order to obtain films with a final thickness around $300 \mathrm{~nm}$. Film crystallisation was accomplished by direct insertion in a conventional furnace at $650^{\circ} \mathrm{C}$. $\mathrm{PbO}$ volatilisation is known to occur at the initial stages of the treatment. The average $\mathrm{Pb} / \mathrm{Ti}$ has been shown to decrease from the initial 0.88 to $\sim 0.8$ during the initial 12 minutes, and to maintain a constant value after that interval, even if the treatment is prolonged for 12 hours. The pyrochlore to perovskite transformation occurs during this period of time (6). Two films were thermally treated for $12 \mathrm{~min}$ and 12 $\mathrm{h}$ for this study. The presence of different amounts of pyrochlore phase, and so different stages of the transformation, was confirmed by grazing incidence X-ray diffraction (GIXRD) with a Siemens D-500 diffractometer with a $\mathrm{Cu}$ anode and equipped with a soller slit.

Plan view specimens for TEM were prepared from $3 \mathrm{~mm}$ discs cut from the films. These discs were mechanically polished from the Si side up to $100-200 \mu \mathrm{m}$, and then dimpled up to $20-30 \mu \mathrm{m}$. Ion erosion with $3.8 \mathrm{keV}$ Ar was used to reach electron transparency $(100 \mathrm{~nm})$. A final ion polishing was accomplished from both sides to remove contamination. Cross section specimens were prepared by using a Gatan cross sectional TEM specimen preparation kit. The specimens were cooled with liquid nitrogen during the final stages of the ion erosion. Most of TEM work was accomplished at $200 \mathrm{kV}$ with a JEOL 2000FX microscope, except the microdiffraction and microanalysis experiments, which were done at $300 \mathrm{kV}$ with a Philips CM30 apparatus.

\section{RESULTS AND DISCUSSION}

The GIXRD pattern of the film thermally treated for 12 minutes is shown in Figure 1a. Peaks labelled with Pe correspond to the perovskite phase while those labelled with Py correspond to the pyrochlore type structure phase (same structure that $\mathrm{Pb}_{2} \mathrm{Ti}_{2} \mathrm{O}_{6}$, JCPDF-ICDD file $\mathrm{n}^{\mathrm{o}}$ 26-142). Miller indexation and planar distances are given in the figure. The intensity relations between the Pe peaks indicate the absence of crystallographic texture. The small peak of $\mathrm{TiO}_{2}$ originated in the substrate. Note the presence of a significant amount of pyrochlore phase. A TEM image of a plan view specimen prepared from this film is shown in Figure 1b. The microstructure is homogenous, with grains with $50-100 \mathrm{~nm}$ size and some intergranular porosity. A large selected area electron diffraction (LAED) pattern is shown in Figure 1c. The pattern is typical for a non-textured polycrystal. The diffraction rings correspond to the planar distances of the perovskite structure. Diffraction spots corresponding with the (222) planar distance of the pyrochlore structure are also present in the LAED as can be seen in the detail shown in Figure 1d. Therefore, intermediate phase grains are present in the specimen, though they are morphologically identical to the perovskite grains. A grain by grain search for non-perovskite planar distances was accomplished by microdiffraction $(25-40 \mathrm{~nm}$ beam size, $\sim 70$ $\mathrm{nm}$ average grain size). The search was focused on the (111) of the pyrochlore, $d_{111}=6.06 \AA$, for simplicity (the $(001) /(100)$
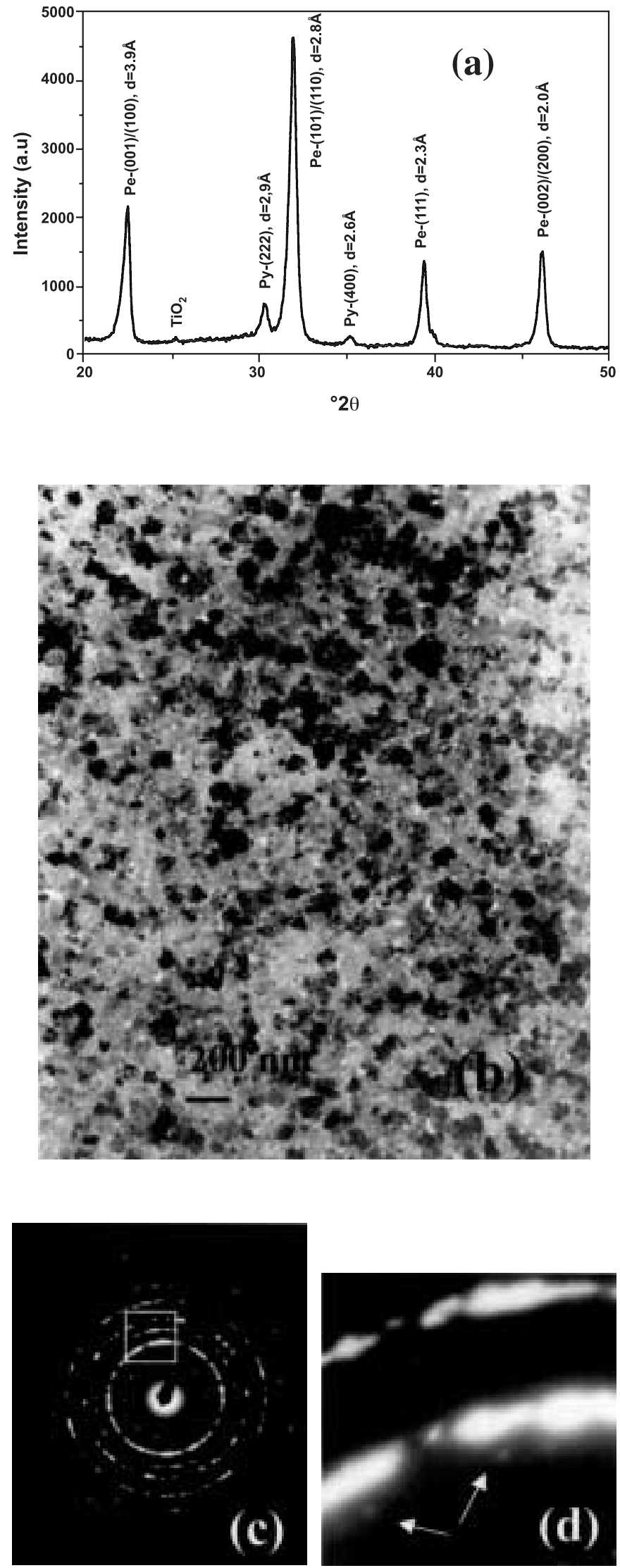

Figure 1. (a) GIXRD pattern for the PTL film treated for 12 minutes, (b) TEM image, (c) LAED pattern and (d) detail of the LAED where Py-(222) spots are marked, for a plan view specimen from this film. 

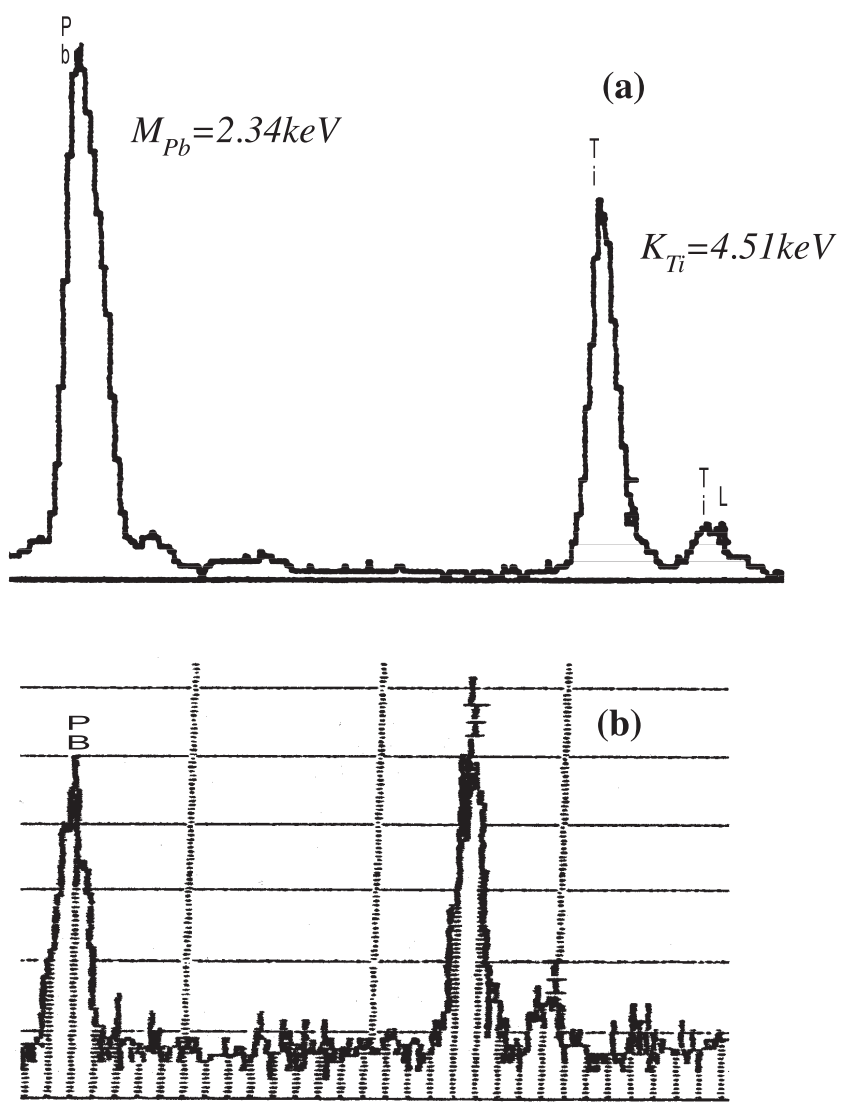

energy $(\mathrm{keV})$

Figure 2. (a) EDXS spectrum for a large area (many grains) of a plan view specimen from the PTL film treated for 12 minutes, and (b) spectrum of a grain (25-40 $\mathrm{nm}$ beam size) with planar distances that are neither consistent with the perovskite structure nor with the pyrochlore structure, in the same film.

perovskite planar distance is $3.9 \AA$ ). A few grains with planar distances, $d$, higher than those of the perovskite structure were found, though d values did not correspond to those of the $\mathrm{Pb}_{2} \mathrm{Ti}_{2} \mathrm{O}_{6}$ structure. These grains showed a $\mathrm{Pb}$ deficiency significantly higher than the average one as it is illustrated in Figure 2.

The GIXRD pattern of the film treated for 12 hours is shown in Figure 3a. The pyrochlore structure diffraction peaks have disappear. A TEM image of a plan view specimen prepared from this film is shown in Figure $3 b$. The microstructure is very similar to that shown by the former film, except for the presence of some textured grain clusters, which seems to indicate the occurrence of a limited abnormal grain growth. This is well illustrated by the selected area electron diffraction (SAED) pattern of the cluster marked in Figure 3b, shown in Figure 3c. The spot striking indicates a slight misalignment of the grains in the cluster. The grain by grain microdiffraction search for the $\mathrm{d}=6.06 \AA$ planar distance was also accomplished in this film. As in the film treated for only 12 minutes, a few grains with planar distances higher than the perovskite ones were found, and neither did they correspond to the pyrochlore structure. Microanalysis showed that these grains were also more $\mathrm{Pb}$ deficient than the film.
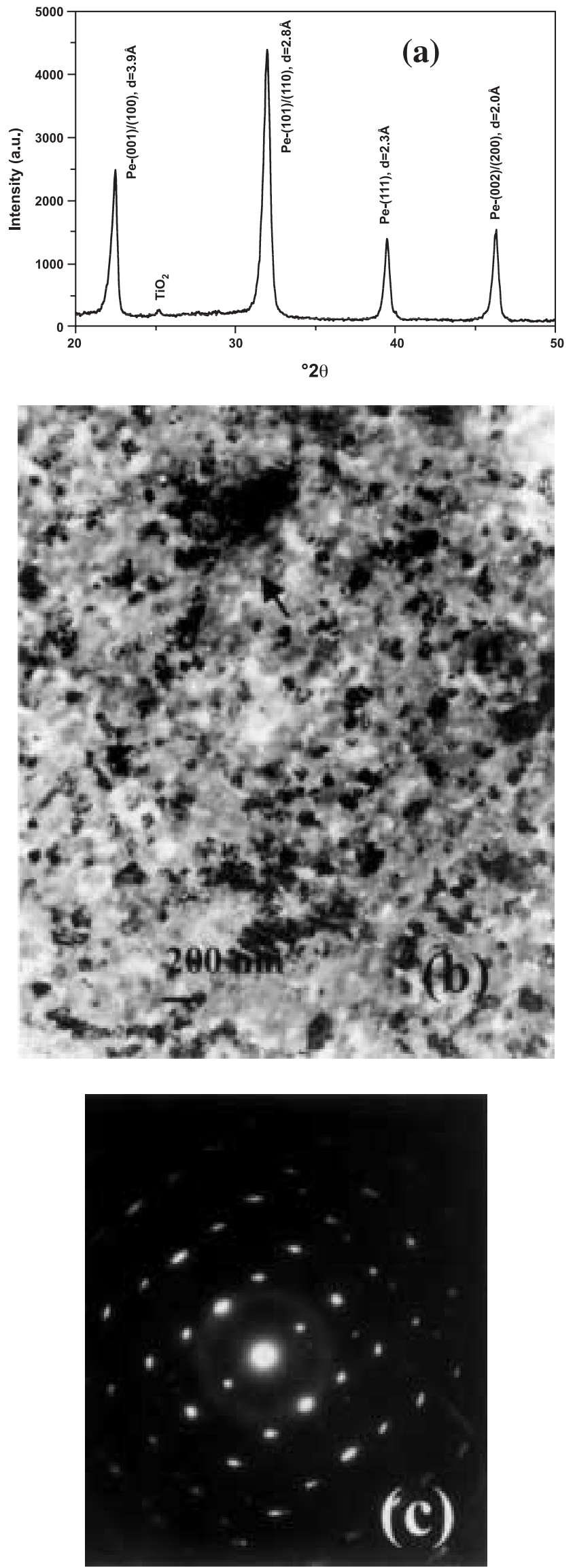

Figure 3. (a) GIXRD pattern for the PTL film treated for 12 hours, (b) TEM image, (c) SAED pattern of the cluster of grains marked with an arrow in (b), for a plan view specimen from this film. 
TEM images of cross section specimen from the two films are shown in Figure 4. There are no microstructural gradients in any of the two. SAED patterns are also shown in the Figure. The perovskite rings are not so well defined as in the LAED of Figure 1c, which is just due to the smaller number of perovskite grains in the area selection. The patterns also showed (222) pyrochlore spots. The thickness distribution of the pyrochlore phase was roughly investigated by moving the area selection, but all SAEDs showed (222) spots. Some limited grain and pore growth with the duration of the treatment is apparent from the images.

The presence of the highly $\mathrm{Pb}$ deficient grains located by microdiffraction, which do not seem to be the intermediate phase observed by GIXRD, seems to support the idea that the perovskite resulting from the transformation has a $\mathrm{Pb} / \mathrm{Ti}$ ratio closer than 0.8 to the nominal 0.88 value. Unfortunately, this investigation failed to find the pyrochlore grains that were transforming into perovskite, and generated the XRD diffraction peaks and ED spots. They are morphologically identical to the perovskite one, and the sensitivity of microdiffraction, significantly worse than that of XRD or SAED, is not high enough to distinguish the pyrochlore microdiffraction spots from the perovskite ones. The phase is in the film as it appears in SAED, and these experiments suggested it was distributed homogenously across the film. Therefore, the substrate/layer interface does not seem to play any special role in the perovskite nucleation process.

\section{CONCLUSIONS}

There are not morphological differences between the pyrochlore phase and the perovskite phase in which it is being transformed into during the rapid heating of sol-gel lanthanum modified lead titanate ferroelectric thin films on $\mathrm{Pt} / \mathrm{TiO}_{2} / \mathrm{Si}$ substrates. This phase can be detected by standard electron diffraction, though it is hardly impossible to distinguish it from the perovskite by microdiffraction. A few highly $\mathrm{Pb}$ deficient, i.e. with a $\mathrm{Pb}$ deficiency higher than the average one, grains with planar distances that were neither consistent with the perovskite structure nor with the pyrochlore one were found in the films by microdiffraction. Its presence is an indirect indication that the perovskite formed during the transformation has a $\mathrm{Pb} / \mathrm{Ti}$ ratio equal or close to the nominal ratio. Neither microstructural nor structural in depth gradients were found in cross section TEM specimens, which indicates that the transformation does not start at the substrate/layer interface, but all across the film. A limited grain and pore growth, as well as growth of local texturing occur along with the phase transformation.

\section{ACKNOWLEDGEMENTS}

This work was funded by the European Commission (EC) through a Copernicus project ref. ERBCIPACT94-0236. Authors also want to thank CEMES-CNRS (Toulouse, France), and Dr. Etienne Snoeck for the access given to their TEM facilities, via the EC COST514 Action.
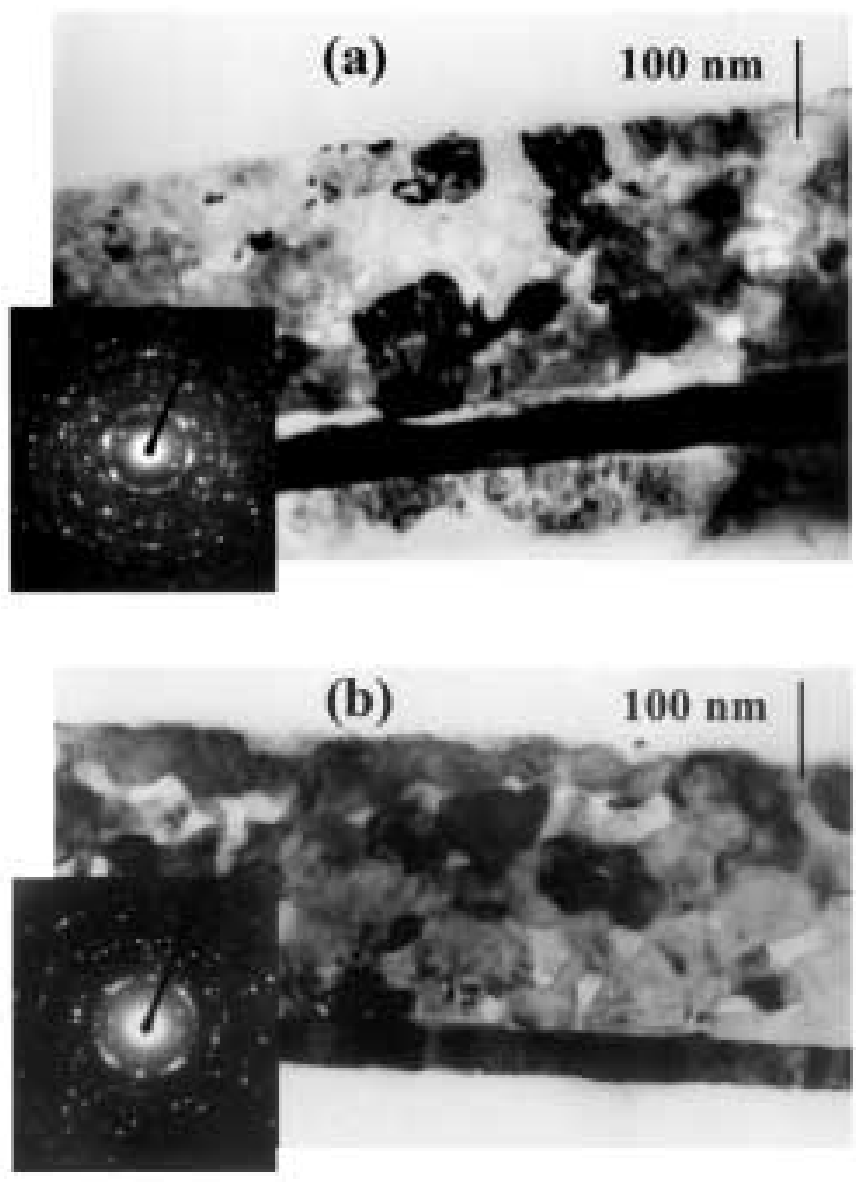

Figure 4. TEM image and SAED of cross section specimens from (a) the PTL film treated for 12 minutes, and (b) the PTL film treated for 12 hours.

\section{REFERENCES}

1. B.A. Tuttle, T.J. Headley, B.C. Bunker, R.W. Schwartz, T.J. Zender, C.L. Hernandez, D.C. Goodnow, R.J. Tissot, J. Michael. "Microstructural evolution of $\mathrm{Pb}(\mathrm{Zr}, \mathrm{Ti}) \mathrm{O}_{3}$ thin films prepared by hybrid metallo-organic decomposition". J. Mater. Res. 7[7], 1876-1882 (1992).

2. A. Seifert, F. Lange, J. Speck. "Epitaxial growth of $\mathrm{PbTiO}_{3}$ thin films on (001) $\mathrm{SrTiO}_{3}$ from solution precursors". J. Mater. Res. 10[3], 1455-1458 (1995).

3. C.D.E. Lakeman, Z. Xu, D. Payne. "On the evolution of structure and composition in sol-gel derived lead zirconate titanate thin films". J. Mater. Res. 10[8], 2042-2051 (1995).

4. E.K.F. Dang, R.J. Gooding. "Theory of the effects of rapid thermal annealing on thin film crystallisation". Phys. Rev. Lett. 74[19], 3848-3851 (1995).

5. K.G. Brooks, I.M. Reaney, R. Klissurska C. Pawlaczyk, N. Setter. "Orientation of rapid thermally annealed lead zirconate titanate thin films on (111) Pt substrates". J. Mater. Res. 9[10], 2540-2553 (1994).

6. I.M. Reaney, K. Brooks, R. Klissurska, C. Pawlaczyk, N. Setter. "Use of transmission electron microscopy for the characterisation of rapid thermally annealed, solution gel, lead zirconate titanate thin films". J. Am. Ceram. Soc. 77[5], 1209-1216 (1994).

7. M. Algueró, M.L. Calzada, L. Pardo. "Pyrochlore-to.perovskite transformation during rapid heating of sol-gel $(\mathrm{Pb}, \mathrm{La}) \mathrm{TiO}_{3}$ thin films". J. Mater. Res. 14[11], 4302-4306 (1999).

8. M.L. Calzada, M. Algueró, L. Pardo. "Chemistry-crystallisation-microstructure relations of sol-gel derived lanthanum modified lead titanate thin films". J. Sol-Gel Sci. Technol. 13, 837-841 (1998).

Recibido: 31.05 .01

Aceptado: 10.12 .01 